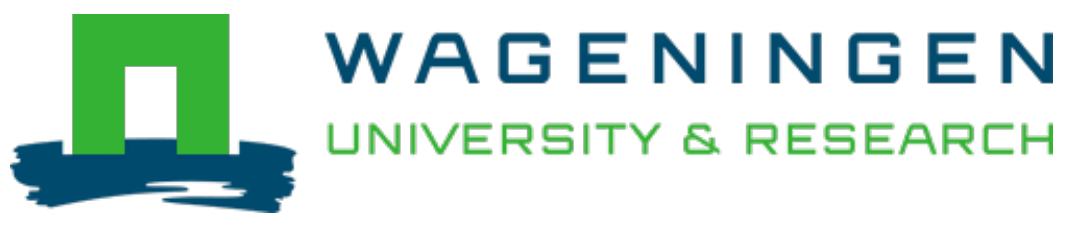

\title{
Trends in somatic cell count deteriorations in Dutch dairy herds transitioning to an automatic milking system
}

\author{
Journal of Dairy Science \\ Borne, Bart H.P.; Grinsven, Niek J.M.; Hogeveen, Henk \\ https://doi.org/10.3168/jds.2020-19589
}

This article is made publicly available in the institutional repository of Wageningen University and Research, under the terms of article $25 \mathrm{fa}$ of the Dutch Copyright Act, also known as the Amendment Taverne. This has been done with explicit consent by the author.

Article 25 fa states that the author of a short scientific work funded either wholly or partially by Dutch public funds is entitled to make that work publicly available for no consideration following a reasonable period of time after the work was first published, provided that clear reference is made to the source of the first publication of the work.

This publication is distributed under The Association of Universities in the Netherlands (VSNU) 'Article $25 \mathrm{fa}$ implementation' project. In this project research outputs of researchers employed by Dutch Universities that comply with the legal requirements of Article $25 \mathrm{fa}$ of the Dutch Copyright Act are distributed online and free of cost or other barriers in institutional repositories. Research outputs are distributed six months after their first online publication in the original published version and with proper attribution to the source of the original publication.

You are permitted to download and use the publication for personal purposes. All rights remain with the author(s) and / or copyright owner(s) of this work. Any use of the publication or parts of it other than authorised under article $25 \mathrm{fa}$ of the Dutch Copyright act is prohibited. Wageningen University \& Research and the author(s) of this publication shall not be held responsible or liable for any damages resulting from your (re)use of this publication.

For questions regarding the public availability of this article please contact openscience.library@,wur.nl 


\title{
Trends in somatic cell count deteriorations in Dutch dairy herds transitioning to an automatic milking system
}

\author{
Bart H. P. van den Borne, ${ }^{*}$ ๑ Niek J. M. van Grinsven, $(1)$ and Henk Hogeveen $(1)$ \\ Business Economics Group, Wageningen University and Research, P.O. Box 8130, 6700 EW Wageningen, the Netherlands
}

\begin{abstract}
Udder health is at risk when herds transition from a conventional milking system (CMS) to an automatic milking system (AMS). Somatic cell counts (SCC) are generally elevated for several months following a transition. However, such observations were made in studies conducted in the early 2000s. Technical improvements to AMS have likely been made since then, and farm management may have improved, learning from past experiences. This longitudinal observational study quantified national trends in SCC deteriorations in dairy herds that transitioned from a CMS to an AMS. Census data from the Dutch test day recording was used to determine these trends. It consisted of all cowlevel SCC measurements conducted in the Netherlands from January 1, 2007 to December 31, 2019. Three udder health indicators, including the natural logarithm of the yield-corrected bulk-milk SCC, the proportion of cows having a composite SCC $\geq 200,000$ cells $/ \mathrm{mL}$, and the proportion of cows having a new elevated SCC, were evaluated using multivariable populationaveraged generalized estimation equations. Predicted values resulting from these statistical models were interpreted to determine trends in SCC deteriorations from 12 mo before and 12 mo after the transition to an AMS. Decreasing SCC deteriorations were observed during the study period for all 3 udder health indicators. Udder health deteriorations around the transition to an AMS were still observed, but they decreased in magnitude over the course of the study period. Bulkmilk SCC deteriorations were, for instance, 2.5 times lower in 2019 compared with those observed in 2007. Therefore, the effect of transitioning to an AMS on udder health became less severe in more recent years. However, deteriorations in the proportion of new SCC elevations were still evident toward the end of the study period. Efforts to lower udder health deteriorations in herds that transition to an AMS should therefore be
\end{abstract}

Received September 4, 2020.

Accepted November 12, 2020.

*Corresponding author: bart.vandenborne@wur.nl continued and should intensify on factors lowering the proportion of cows having a new elevated SCC.

Key words: robotic milking, subclinical mastitis, milk quality, dairy cattle

\section{INTRODUCTION}

Automatic milking systems (AMS) have become an established milking technology globally. They reduce the need for labor, may improve animal welfare, and offer the possibility for an increased milk yield in comparison with conventional milking systems (CMS; Jacobs and Siegford, 2012). The number of dairy farms milking with an AMS have therefore steadily been increasing since the first system was installed in the Netherlands in 1992. In 2015, it was estimated that there were more than 25,000 dairy farms with an AMS worldwide, with the majority being installed in western Europe and North America (Barkema et al., 2015). In $2019,26 \%$ of the Dutch dairy herds had an AMS, and $70 \%$ of the newly installed milking systems concerned an AMS (KOM, 2020).

Udder health may potentially improve in herds that milk with an AMS. In comparison with herds that milk with a CMS, milking with an AMS is at the quarter level and based on the cows' milk production and milking frequency. Additionally, liners are flushed and often steamed after each milking. This is all considered to be beneficial from an udder health perspective. Nonetheless, udder health is at risk in practice when dairy herds transition from a CMS to an AMS. Generally, increased SCC levels are observed for several months in herds that transition to an AMS (Klungel et al., 2000; Kruip et al., 2002; de Koning et al., 2003; Mulder et al., 2004; Rasmussen, 2006; Hovinen et al., 2009), as reviewed by Hovinen and Pyörälä (2011) and, more recently, by Penry (2018) and Hogenboom et al. (2019). However, the studies included in the reviews were published in the early 2000s, and advances have likely been made since then. Experiences from the past, both scientific and practical, may have triggered farmers to pay attention to mastitis prevention before the transition. Indeed, it is common practice nowadays to advise farmers to lower 
SCC levels before transitioning to an AMS. Moreover, technological advances may have contributed to less marked udder health deteriorations. It is not known, however, whether these efforts have indeed resulted in a smoother transition regarding udder health. Additionally, national SCC levels have steadily been decreasing in the Netherlands over the last decade. The national geometric mean bulk-milk SCC (BMSCC) decreased from 209,000 cells $/ \mathrm{mL}$ in 2010 to 171,000 cells $/ \mathrm{mL}$ in 2018 (ZuivelNL, 2019) and may partly explain a possible smoother transition. A trend analysis of SCC deteriorations when herds transition from a CMS to an AMS can determine whether improvements have been made. Additionally, the analysis indicates whether further attention is needed.

The aim of this study was to analyze national trends in SCC deteriorations of Dutch dairy herds transitioning from a CMS to an AMS.

\section{MATERIALS AND METHODS}

Census data from the Dutch test day recording was analyzed in this longitudinal observational study. Data were provided by CRV (Arnhem, the Netherlands) and spanned over a 13-yr period from January 1, 2007 until December 31, 2019. The proportion of farmers participating in the test day recording increased from $80.2 \%$ to $87.6 \%$ during this period (CRV, 2020). The provided data were anonymized to comply with privacy regulations and consisted of both cow level (e.g., milk production, SCC, date of calving) and herd-level test day recording data. Cow-level data were used to determine udder health indicators, and herd-level data were used to define the moment of transition from a CMS to an AMS.

\section{Udder Health Indicators}

Not all cows participating in the Dutch test day recording have their SCC consistently measured when they are tested. Therefore, cow-level test day recordings that were either missing a SCC measurement or were within the first $3 \mathrm{~d}$ after calving (Barkema et al., 1999) were excluded. Cow-level recordings were then aggregated at the herd level to allow an evaluation of 3 udder health indicators. The natural logarithm of the yield-corrected BMSCC of the herd, the primary outcome of this study, was calculated first at each test day as follows:

$$
\ln \left(B M S C C_{j}\right)=\frac{\sum\left(m i l k_{i j} \times S C C_{i j}\right)}{\sum m i l k_{i j}},
$$

with milk $_{i j}$ and $S C C_{i j}$ representing the milk production and SCC from cow $i$ at test day $j$, respectively. Furthermore, the proportion of cows at each test day having a composite $\mathrm{SCC} \geq 200,000$ cells $/ \mathrm{mL}$ (pHIGH) was defined as the prevalence of subclinical mastitis (van den Borne et al., 2010) and analyzed as a secondary outcome. Cows with a SCC $<200,000$ cells $/ \mathrm{mL}$ at the previous test day and a SCC $\geq 200,000$ cells $/ \mathrm{mL}$ at the current test day were considered to have a new elevated SCC. Subsequently, the proportion of cows having a new elevated SCC (pNEW) at the current test day relative to the number of cows with a low SCC at the previous test day was defined for each test day. This last udder health indicator was assumed to be indicative for the new subclinical infection rate and was analyzed as a secondary outcome also.

\section{Definition of Transition to an AMS}

Herd-level test day recordings that were not within 6 mo of each other were removed first. Thereafter, the date of transition from a CMS to an AMS was defined. In the herd-level data, a binary variable at each test day indicated whether the test day milk samples were obtained from an AMS or a CMS. This information was used to evaluate SCC deteriorations around the transition from CMS to AMS. The exact date of the transition from a CMS to an AMS is not recorded. Therefore, if the herd used a CMS during the previous test day and an AMS at the current test day, the latter was defined as the day of transition (time 0). Within herds that transitioned to an AMS, the interval length of each test day recording relative to the defined day of transition was calculated and expressed in the number of months as follows:

$$
\begin{aligned}
& \text { Time (in months): } \leq-12,-11,-10,-9,-8,-7, \\
& -6,-5,-4,-3,-2,-1,0,1,2,3,4,5,6,7,8, \\
& 9,10,11 \text {, and } \geq 12,
\end{aligned}
$$

with 0 being the day of transition. Herds that did not transition to an AMS received a different coding and were defined as the reference group. The intercept model, as described below, therefore indicated SCC levels in the reference year of herds that continued milking with a CMS.

\section{Statistical Analysis}

Each udder health indicator was analyzed at the herd level using multivariable population-averaged general- 
ized estimating equations models that had the following general structure:

$$
\begin{aligned}
& Y_{i}=\beta_{0}+\beta_{1} \text { year }+\beta_{2} \text { time }+\beta_{3} \sin (2 m / 12) \\
& +\beta_{4} \cos (2 m / 12)+\varepsilon_{i},
\end{aligned}
$$

where $Y_{i}$ represents 1 of the 3 udder health indicators at test day $i, \beta_{0}=$ the intercept, $\beta_{1}$ to $\beta_{4}=$ regression coefficients, year $=$ categorical variable year of performing the test day recording (this variable is indicative for the annual SCC trend), time = the categorical variable indicating the month relative to the day of transitioning to an AMS, and $\varepsilon=$ the residual error term. A combination of sine-cosine functions was added to all models to correct for seasonal SCC variations (van den Borne et al., 2010). All statistical models corrected for repeated herd-level test day recordings by including a first-order autoregressive correlation structure, which gave the best model fit among competing structures based on the quasilikelihood under the independence model criterion (Cui, 2007). The BMSCC was analyzed with a normal distribution, and a negative binomial distribution was used for pHIGH and pNEW. To correct for differences in herd sizes, the natural logarithm of the number of cows present at the test day recording and the natural logarithm of the number of cows with a low SCC at the previous test day recording, respectively, were included as offsets in the statistical models for pHIGH and pNEW.

The base model [Eq. 1] estimated the annual trend in SCC and SCC deteriorations across all years and all dairy herds. To evaluate whether SCC deteriorations changed over time, a 2-way interaction term between year and time was added to the base model of each of the 3 udder health indicators. These models (results not shown due to the size of the model output) were used to predict SCC deteriorations around transition to an AMS. Additionally, the effect of BMSCC levels before transition on BMSCC levels after transition to an AMS was investigated in a separate analysis. Herds that transitioned from a CMS to an AMS were categorized based on their arithmetic mean BMSCC levels in the year before the transition as follows: $\leq 150,000$ cells $/ \mathrm{mL}$ (low), 151,000 cells $/ \mathrm{mL}$ to 250,000 cells $/ \mathrm{mL}$ (medium), or $\geq 251,000$ cells $/ \mathrm{mL}$ (high). Because this analysis only concerned herds with a transition, herds that continued milking with a CMS were excluded and the defined date of transition (time $=0$ ) was taken as the reference category. The variable BMSCC category before the transition was added to the base model [Eq. 1] as a main effect and as part of an interaction term with time for this subanalysis.
Because census SCC data were analyzed, testing for statistical significance was not useful. Udder health indicators were therefore evaluated for their biological relevance: predicted values resulting from the statistical models were calculated, and if these changed more than 10,000 cells/mL (BMSCC), $2 \%$ (pHIGH), or $1 \%$ (pNEW), they were considered to be biologically relevant (Santman-Berends et al., 2016). All statistical models were created using the xtgee command in Stata 15.1 (StataCorp LLC, College Station, TX).

\section{RESULTS}

The flow of observations at both cow and herd level is depicted in Figure 1. The cleaned cow-level data set had 152,376,610 observations after removing test day recordings with no SCC measurements or that were within 3 DIM. At herd level, intervals between test day recordings lasted more than 6 mo within some herds. These test day recordings, and all their preceding recordings, were excluded, resulting in a cleaned herd-level data set consisting of 2,044,045 observations. After merging the 2 herd-level data sets, observations that were either missing data in 1 of the 2 data sets or were from herds $(\mathrm{n}=37)$ that had multiple CMS to AMS transitions recorded were also excluded from further analysis. This ultimately resulted in an analytical herd-level data set of 19,491 dairy herds with 2,002,884 (BMSCC and pHIGH) and 1,984,287 observations (pNEW) included in the final statistical models.

\section{Study Population}

A characterization of the dairy herd study population is provided in Table 1. A decline in the number of dairy herds was observed from 16,641 (2007) until 14,189 (2019), but this decline was accompanied with an increase in the average herd size from 61 (2007) to 88 (2019) lactating cows. Between 150 and 350 dairy herds transitioned from a CMS to an AMS annually, with this number being the lowest in 2016 and 2017. The average 305-d milk production of herds participating in the test day recording fluctuated around 8,400 $\mathrm{kg}$ in the years 2007 until 2016, after which it increased to close to $9,000 \mathrm{~kg}$ in the last year of the study period.

\section{The BMSCC}

Figure 2 presents the observed monthly arithmetic BMSCC of all dairy herds that participated in the Dutch test day recording from 2007 until 2019. A clear downward trend was observed. The average monthly BMSCC was 230,000 cells/mL in 2007 and decreased to 
174,000 cells/mL in 2019. An obvious seasonal pattern was also visible, with BMSCC levels being higher in the summer period compared with the winter period.
The final statistical models predicting BMSCC, pHIGH and pNEW are presented in Table 2. Similar to Figure 2, the model identified a downward trend

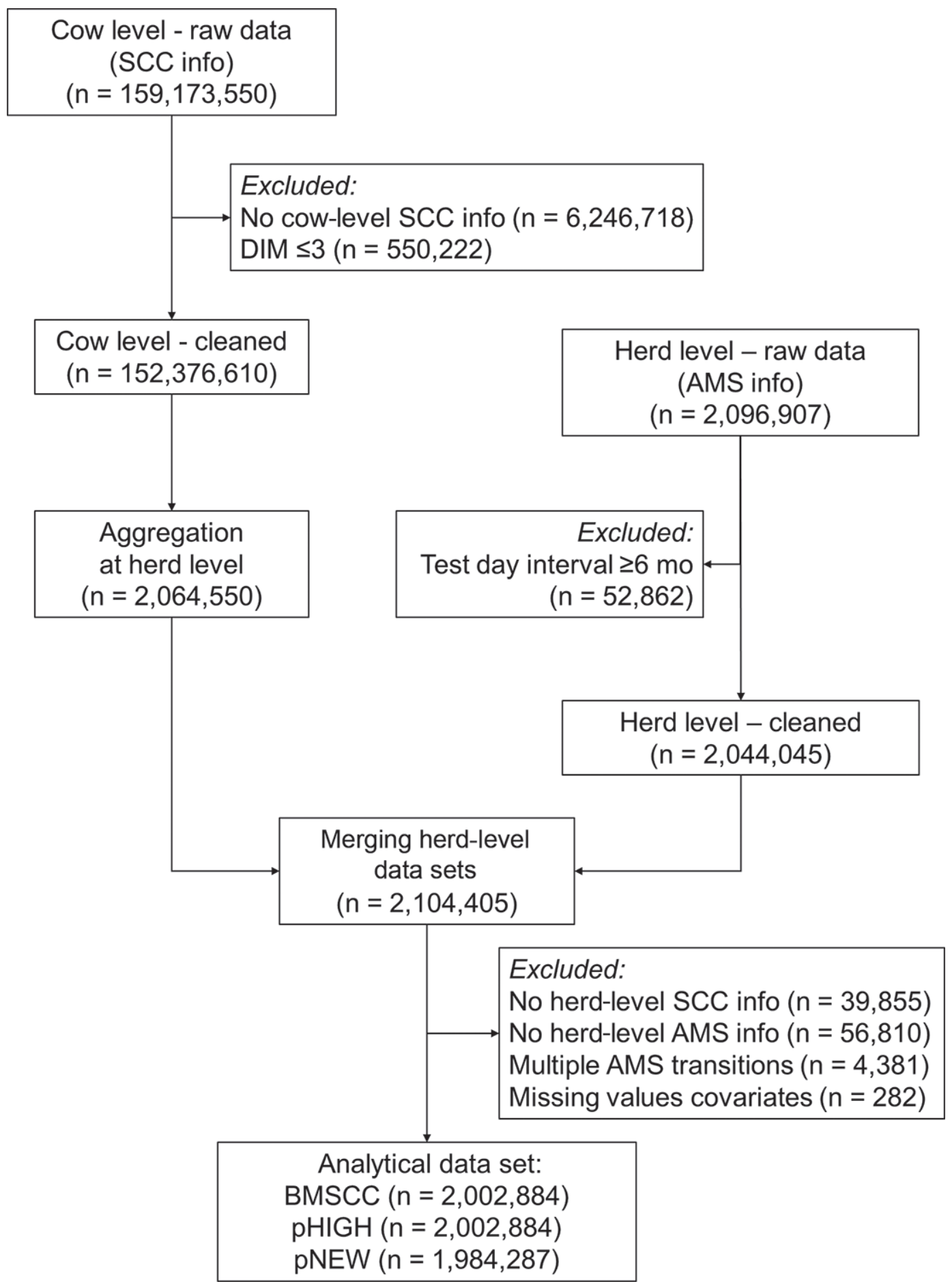

Figure 1. Data flowchart. AMS = automatic milking system; BMSCC = bulk-milk SCC; pHIGH = proportion of cows having a composite $\mathrm{SCC} \geq 200,000$ cells $/ \mathrm{mL} ; \mathrm{pNEW}=$ proportion of cows having a new elevated SCC. 


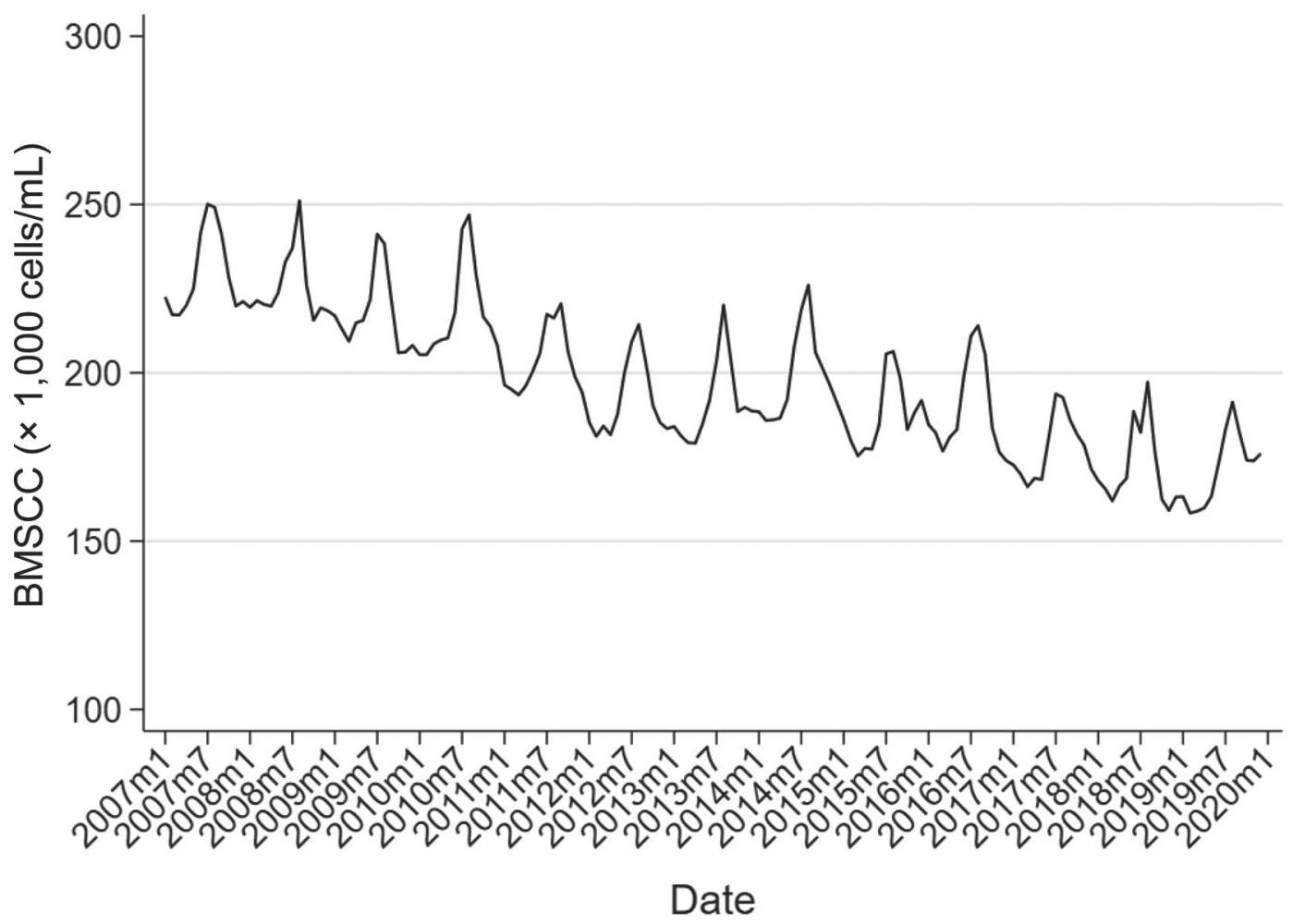

Figure 2. Observed monthly arithmetic bulk-milk SCC (BMSCC) of all dairy herds participating in the Dutch test day recording from January 1, 2007, until December 31, 2019. Dates are presented by year and month (m) number.

in BMSCC across the years. For instance, the natural logarithm of BMSCC was 0.308 units lower in 2019 compared with 2017. Herds that transitioned to an AMS had generally lower BMSCC levels before the transition compared with herds that continued milking with a CMS, but levels became higher after the transition: the coefficients for the variable time switched from negative values before the transition to positive values after the transition. Bulk-milk SCC levels were the highest in the first 5 to 6 mo after the transition, after which they slowly declined again to levels similar to those of the average herd with a CMS.

When evaluating predicted values resulting from the statistical model that included the interaction term between time and year (Figure 3), it became clear that BMSCC deteriorations occurred in all years. However, BMSCC deteriorations became weaker across the study period. Although it was still at a maximum of 20,000

Table 1. Description of herds included in the study

\begin{tabular}{|c|c|c|c|c|c|}
\hline Year & $\begin{array}{l}\text { Number of } \\
\text { dairy herds }\end{array}$ & $\begin{array}{c}\text { Average } 305-\mathrm{d} \\
\text { production }(\mathrm{kg})\end{array}$ & $\begin{array}{l}\text { Average } \\
\text { herd size }\end{array}$ & $\begin{array}{c}\text { Number of } \mathrm{AMS}^{1} \\
\text { herds }(\%)\end{array}$ & $\begin{array}{l}\text { Number of newly } \\
\text { installed AMS (\%) }\end{array}$ \\
\hline 2007 & 16,641 & 8,391 & 61 & $948(5.7)$ & $209(1.3)$ \\
\hline 2008 & 16,418 & 8,372 & 64 & $1,312(8.0)$ & $335(2.0)$ \\
\hline 2010 & 15,900 & 8,509 & 67 & $1973(12.4)$ & $299(1.9)$ \\
\hline 2011 & 15,716 & 8,501 & 69 & $2,306(14.7)$ & $321(2.0)$ \\
\hline 2012 & 15,450 & 8,415 & 72 & $2,644(17.1)$ & $355(2.3)$ \\
\hline 2015 & 15,426 & 8,389 & 82 & $3,424(22.2)$ & $227(1.5)$ \\
\hline 2016 & 15,308 & 8,487 & 88 & $3,555(23.2)$ & $159(1.0)$ \\
\hline 2017 & 15,135 & 8,638 & 87 & $3,688(24.4)$ & $164(1.1)$ \\
\hline 2018 & 14,671 & 8,913 & 85 & $3,846(26.2)$ & $211(1.4)$ \\
\hline 2019 & 14,189 & 8,997 & 88 & $4,016(28.3)$ & $264(1.9)$ \\
\hline
\end{tabular}

\footnotetext{
${ }^{1}$ Automatic milking system.
} 
cells $/ \mathrm{mL}$ in the fifth month after the transition in 2019, and thus considered relevant, it was 2.5 times lower compared with the BMSCC peak in 2007, when it was at a maximum of 52,000 cells $/ \mathrm{mL}$ in the second month after the transition. Since 2011, BMSCC deteriorations in the first 6 mo after the transition were at a maximum of 23,000 cells $/ \mathrm{mL}$ (second and third month after transition in 2018), and thus mostly remained within the 20,000 cells/mL difference range compared with herds that continued milking with a CMS.
Figure 4 depicts predicted BMSCC levels around the transition to an AMS according to 3 BMSCC categories before the transition. Herds that already had a low $(\leq 150,000$ cells $/ \mathrm{mL})$ BMSCC level before the transition were, despite having a peak directly after the transition, still able to continue having BMSCC levels around 150,000 cells/mL on average. Herds that had medium (151,000-250,000 cells/mL) BMSCC levels before the transition experienced a maximum increase of 24,000 cells $/ \mathrm{mL}$ after the transition on average. A

Table 2. Results of the final statistical models for the natural logarithm of bulk-milk SCC, the proportion of cows with an elevated SCC $(\geq 200,000$ cells $/ \mathrm{mL} ; \mathrm{pHIGH})$, and the proportion of cows with a new elevated SCC (pNEW)

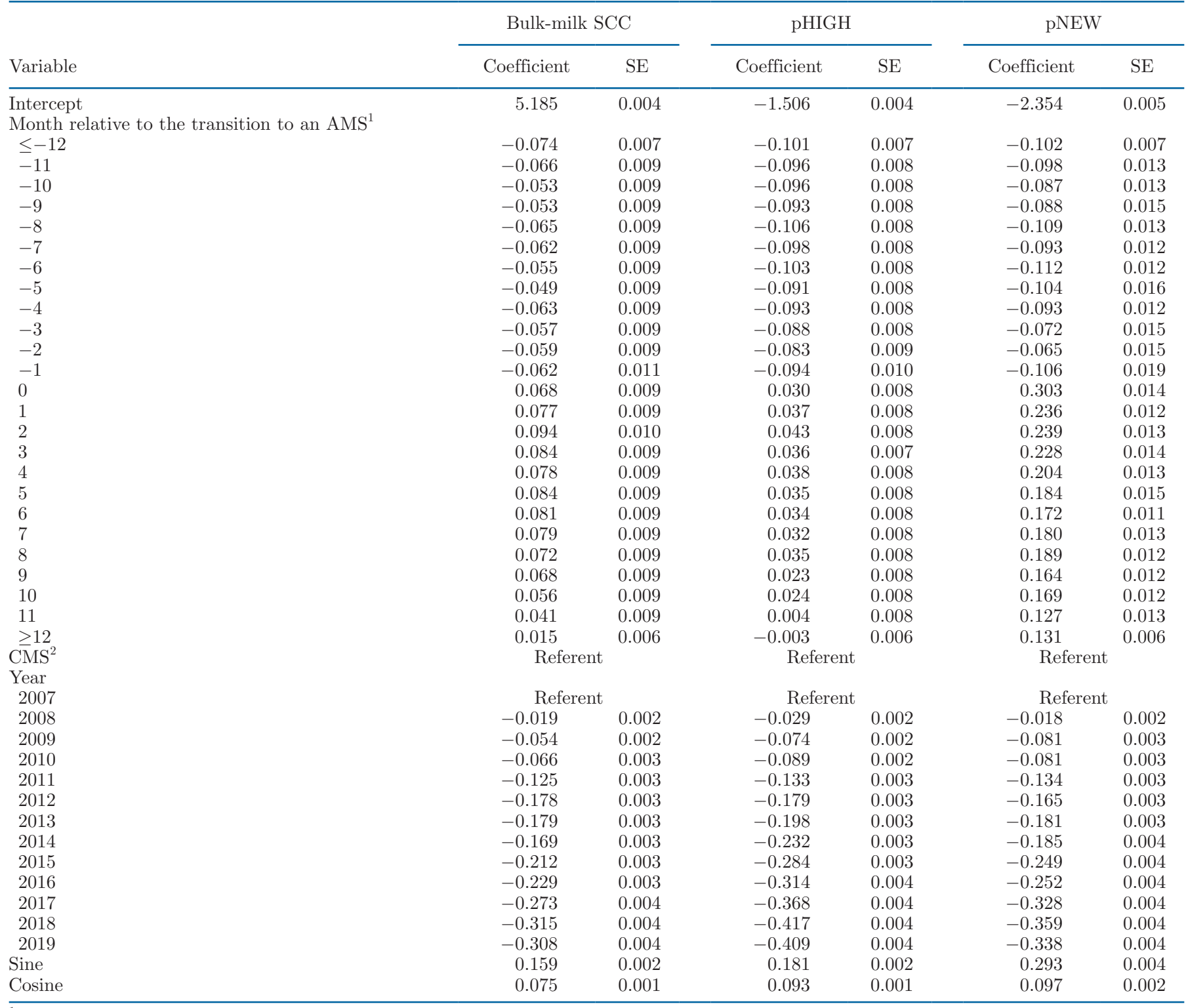

${ }^{1}$ Automatic milking system.

${ }^{2}$ Herds with a conventional milking system. 
BMSCC deterioration could not be observed in herds that already had a high $(\geq 251,000$ cells $/ \mathrm{mL})$ BMSCC level before the transition. Those herds continued to have high BMSCC levels for a few months after the transition until they started to decline.

\section{The $\mathrm{pHIGH}$}

The mean proportion of cows with an elevated SCC showed a pattern similar to that of BMSCC. Both a steady declining trend, from $26.5 \%$ in 2007 to $17.4 \%$ in 2019, and a seasonal pattern could be observed for pHIGH (Figure 5). These 2 graphical observations were confirmed by the statistical model (Table 2). Relative to herds that continued milking with a CMS, the statistical model also revealed lower pHIGH levels before the transition, elevated pHIGH levels for $10 \mathrm{mo}$ after the transition, and a decline to lower pHIGH levels thereafter.
When evaluating pHIGH deteriorations across the study period (Figure 6), it became clear that pHIGH deteriorations, similar to those of BMSCC again, became less severe with an advancing study period. Whereas pHIGH deteriorations were at a maximum of $6.3 \%$ in the fourth month after transition in 2007, these generally remained, with a few exceptions, within the $2 \%$ difference range since 2012, although pHIGH deteriorations were shortly up to $3.4 \%$ and $3.8 \%$ again in, respectively, 2015 and 2016.

\section{The pNEW}

A declining annual trend was also visible for the mean monthly pNEW, although it was less strong compared with the 2 other udder health indicators. The mean monthly pNEW decreased from $13.2 \%$ in 2007 to $10.5 \%$ in 2019 (Figure 5), and the median yearly pNEW decreased from $12.0 \%$ to $8.7 \%$. An annual trend
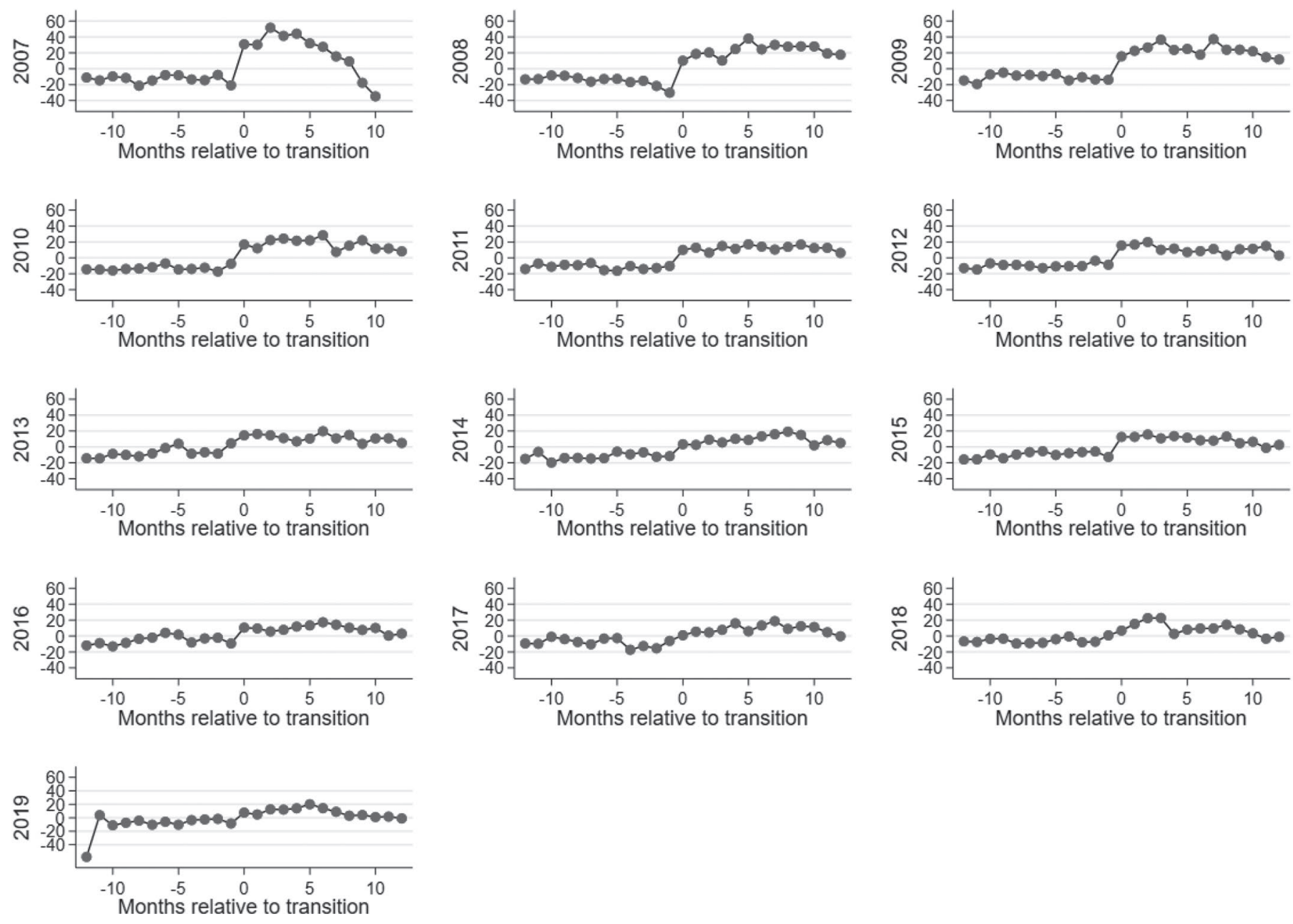

Figure 3. Predicted bulk-milk SCC deteriorations (in 1,000 cells/mL) in Dutch dairy herds transitioning to an automatic milking system relative to herds with a conventional milking system according to year of transition. 


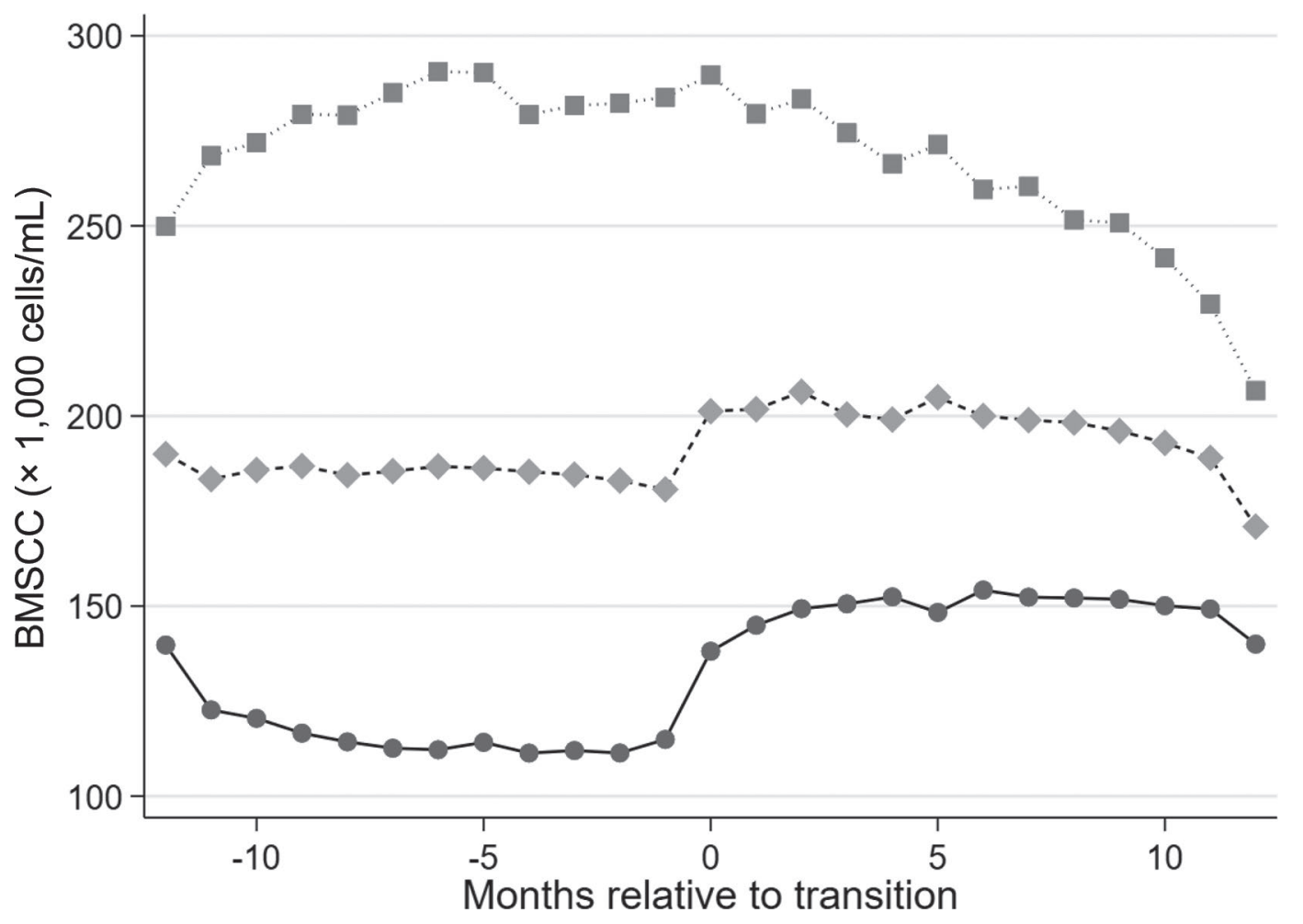

Figure 4. Predicted bulk-milk SCC (BMSCC) in Dutch dairy herds transitioning to an automatic milking according to 3 BMSCC levels before the transition $(\leq 150,000$ cells $/ \mathrm{mL}=$ dot; $151,000-250,000$ cells $/ \mathrm{mL}=$ diamond; $\geq 251,000$ cells $/ \mathrm{mL}=$ square $)$.

toward lower pNEW levels became apparent in the statistical model (Table 2). Moreover, pNEW levels were again lower before the transition, peaked directly after transition, and decreased again in the months after the transition relative to herds that continued milking with a CMS.

Predicted pNEW deteriorations after the transition to an AMS were of a relatively similar magnitude across the study period as observed graphically (Figure 7). The strongest pNEW deteriorations were observed in the first $3 \mathrm{yr}$ of the study period (2007-2009), with the difference being more than $3 \%$, but substantial pNEW deteriorations of $\geq 2 \%$ were also observed each year in the rest of the study period (Figure 7). The highest predicted pNEW deteriorations were mostly observed in the month of transition ( time $=0$ ), but pNEW deteriorations of up to and above $2 \%$ could also be observed in other months following the transition, including the more recent years of 2015, 2016, 2017, and 2019.

\section{DISCUSSION}

It is well-known that dairy herds that transition to an AMS temporarily experience SCC deteriorations (Hovinen and Pyörälä, 2011; Penry, 2018; Hogenboom et al., 2019). Such observations have been made in numerous studies before. For instance, Hovinen et al. (2009) observed higher cow SCC levels for up to 12 mo after the transition in 88 Finnish dairy herds. In the study by Rasmussen (2006), a significant increase in BMSCC was observed in 478 Danish dairy herds. Similar findings were observed by de Koning et al. (2003) in 262 Dutch and 99 Danish herds, but not in 33 German herds. Reduced milk quality was especially seen in the first years after the introduction of AMS to the dairy industry (Klungel et al., 2000; Rasmussen et al., 2002). The current investigation, using census data from the Dutch test day recording and covering a more recent time frame from 2007 to 2019, confirmed these earlier studies. Deteriorations in BMSCC, pHIGH, and pNEW still occurred in herds that transitioned to an AMS. However, their magnitude became less strong over the years. In particular, improvements were observed since 2011 and 2012. The difference in BMSCC and pHIGH was at a maximum of 20,000 cells $/ \mathrm{mL}$ and $2.5 \%$, respectively, in 2019 between herds that transitioned to an AMS and herds that continued milking with an CMS. Although a 20,000 cells/mL difference in BMSCC is still considered relevant (Santman-Berends et al., 2016), these temporarily SCC deteriorations are manageable from an udder health perspective. The latter is confirmed by the current study in which herds 
that transition to an AMS managed to, since 2012, lower their BMSCC levels within 1 yr to levels similar to those of the average CMS herd.

The less severe SCC deteriorations observed in more recent years may be due to technical improvements of the AMS, to dairy farmers anticipating a transition by lowering their SCC levels, to farmers' mastitis management during and directly after the transition, or to the decreasing trend in BMSCC occurring in the Netherlands during the study period (this study; ZuivelNL, 2019). The statistical models corrected for the downward SCC trend and therefore did not explain the fact that SCC deteriorations became less severe. Moreover, improvements in BMSCC (or pHIGH) before the transition to an AMS could not directly be observed, either (Figures 3 and 6). A first reason that could explain the less marked SCC deteriorations when transitioning to an AMS in more recent years is believed to be the technical advances of the AMS. Different technical advances, such as steam cleaning, exist between the various AMS brands available in the market, but are not always installed. Such detailed information was unfortunately not at our disposal and could not be used to explain the less marked SCC deteriorations observed in more recent years. A second reason that could explain the less marked SCC deteriorations is a more aggressive mastitis management by treating more cows with antimicrobials or culling mastitic cows. Slight to substantial increases in the number of cows being treated with antimicrobials after transitioning to an AMS have indeed been reported earlier (Bennedsgaard et al., 2004; Rasmussen, 2006; Hovinen et al., 2009), but such data were not available for the current investigation. Information about the culling of cows is missing from studies investigating SCC deteriorations after transitioning to an AMS, including ours.

Differences in SCC deteriorations between herds with a different BMSCC level before the transition were observed. The largest SCC deterioration was observed in herds with the lowest BMSCC before the transition, but those herds had still the lowest BMSCC levels after the transition. Herds transitioning to an AMS should therefore lower their BMSCC levels to avoid the possibility of receiving a penalty for having a BMSCC above the penalty threshold. On the other hand, no SCC deterioration was observed in herds with a high BMSCC before the transition, which is likely caused by a more aggressive mastitis management of the farmer (i.e., treating more cows with antimicrobials or culling more animals) to stay below the Dutch BMSCC pen-

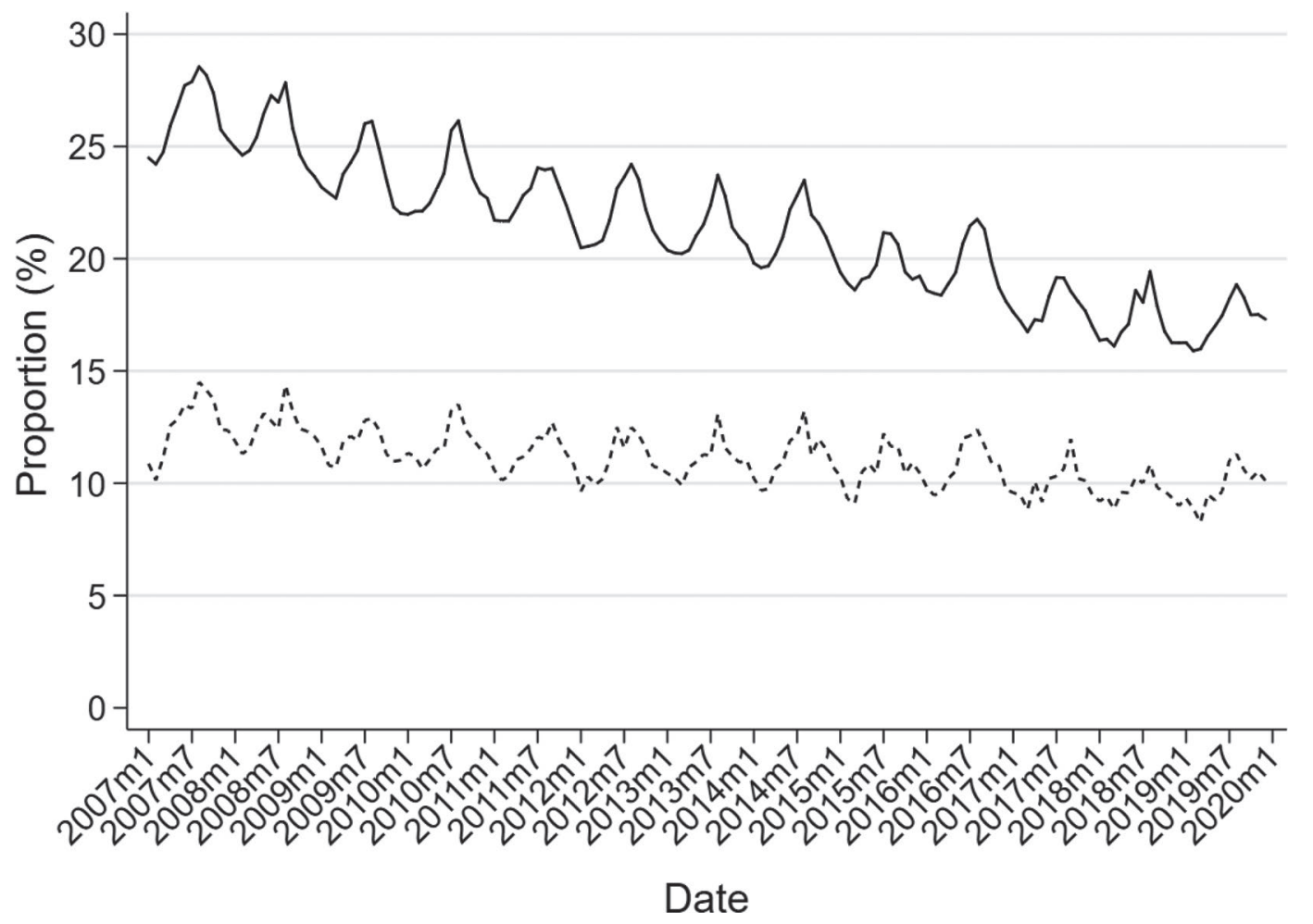

Figure 5. Observed monthly proportion of cows with an elevated SCC ( $\geq 200,000$ cells $/ \mathrm{mL}$; solid line) and proportion of cows with a new elevated SCC (dashed line) of all dairy herds participating in the Dutch test day recording from January 1, 2007, until December 31, 2019. Dates are presented by year and month $(\mathrm{m})$ number. 

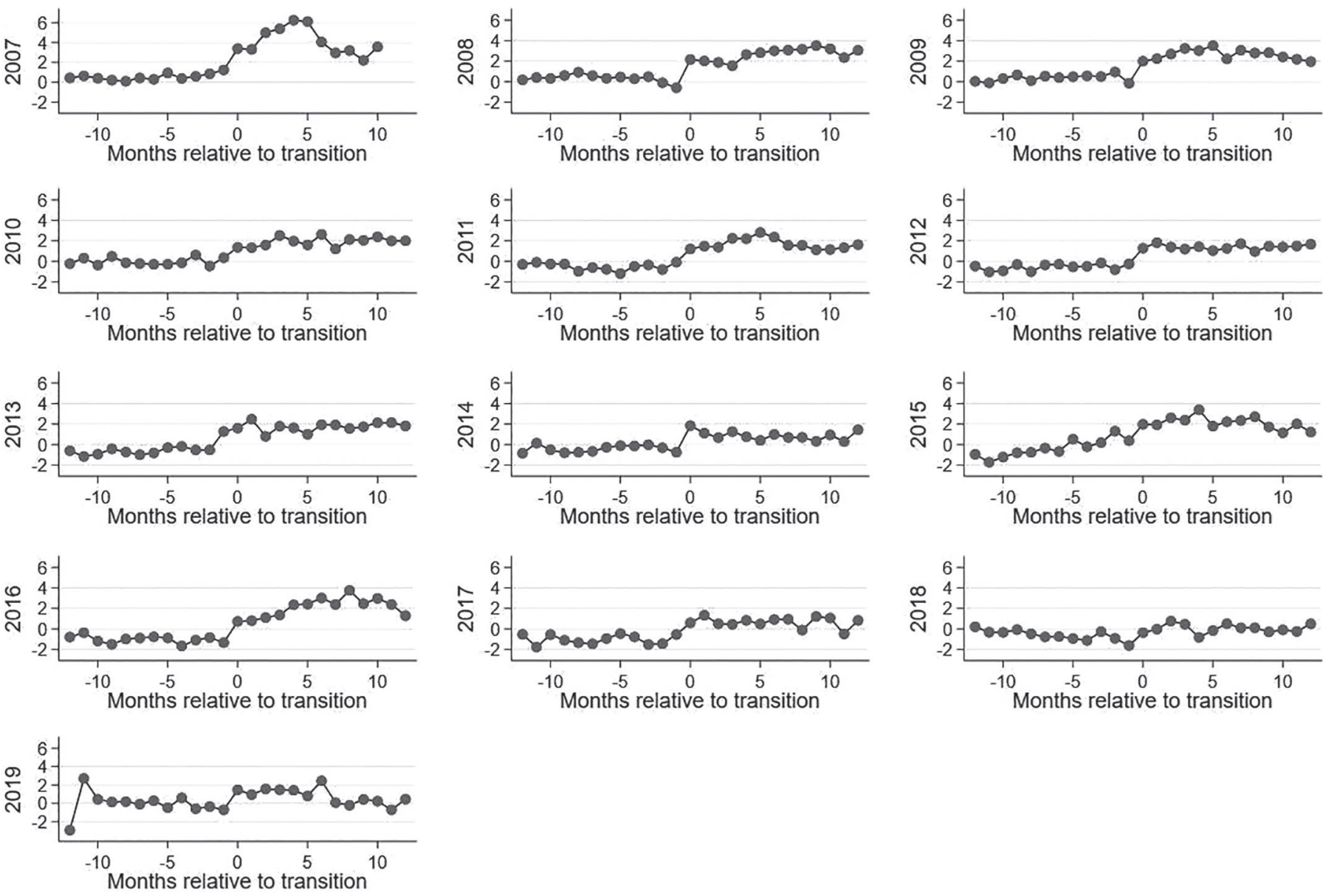

Figure 6. Predicted deteriorations of the proportion of elevated SCC measurements (in \%) in Dutch dairy herds transitioning to an automatic milking system relative to herds with a conventional milking system according to year of transition.

alty level of 400,000 cells/mL. In all 3 BMSCC classes, a movement toward the average CMS herd was seen after the transition. This observation can be explained by the "regression toward the mean" phenomenon (Stigler, 1997).

Yearly predicted values of the 3 udder health indicators (Figures 3, 6, and 7) became less stable toward the end of 2007 and at the beginning of 2019. These fluctuations should, however, be interpreted in light of the relatively small sample sizes at these stages of the study period. Moreover, this observational study was conducted in a population of Dutch dairy herds, which is characterized by a relatively high proportion of dairy herds transitioning to an AMS and a declining national trend in SCC. Nonetheless, the downward trend in SCC deteriorations is likely to also occur in other countries because AMS producers operate, and thus share their knowledge, internationally.

In this study, udder health deteriorations in herds that transitioned from a CMS to an AMS were based on SCC measurements from the national test day recording. However, SCC is only 1 aspect of udder health. Clinical mastitis and antimicrobial usage data, which are also relevant from an udder health perspective, were not available for our analysis. In a recent study, Deng et al. (2020) found no difference in the number of animal-defined daily dosage per year between herds with an AMS and herds with a CMS. However, these authors did not evaluate the time around a transition to an AMS, whereas deteriorations in clinical mastitis and antimicrobial usage may be especially expected in this risk period based on the SCC deteriorations observed in this study and elsewhere.

The statistical models revealed that SCC deteriorations for all 3 udder health indicators became less severe during the study period. To continue this positive trend, a persistent effort to optimize udder health and udder health management around the transition to an AMS is needed. On the other hand, and although there was a downward trend, evident pNEW deteriora- 

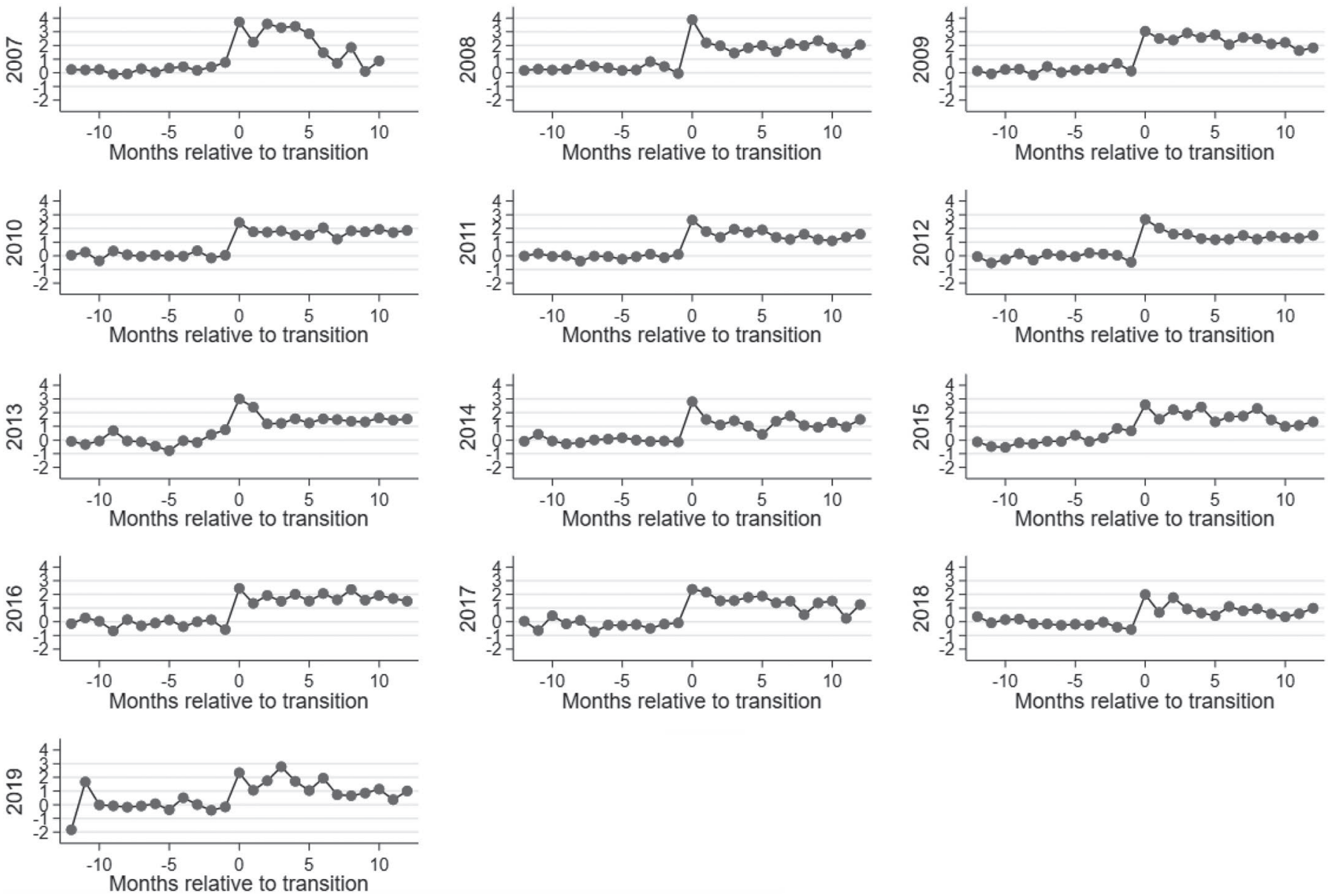

Figure 7. Predicted deteriorations of the proportion of new elevated SCC measurements (in \%) in Dutch dairy herds transitioning to an automatic milking system relative to herds with a conventional milking system according to year of transition.

tions were still occurring in more recent years. Farmers and mastitis workers should therefore be aware that although national SCC deteriorations are decreasing, pNEW deteriorations might still become problematic after transitioning to an AMS and that a continued attention is needed.

\section{CONCLUSIONS}

Using census data from the Dutch test day recording, this study identified that SCC deteriorations were common in herds that transitioned from a CMS to an AMS. In the context of decreasing SCC levels nationally, less strong SCC deteriorations were observed during the 13-yr study period. The BMSCC and pHIGH deteriorations observed in the second half of the study period were considered to be manageable from an udder health perspective. For pNEW, however, it became clear that, although deteriorations were lower toward the end of the study period, they were still considered to be too high in more recent years. Farmers and mastitis workers should therefore continue to pay attention to udder health when herds transition to an AMS. A continued monitoring of trends in SCC deteriorations when herds transition to an AMS is recommended to allow a prompt intervention if needed.

\section{ACKNOWLEDGMENTS}

The authors thank CRV (Arnhem, the Netherlands) for kindly providing the test day recording data. This research did not receive any specific grant from funding agencies in the public, commercial, or not-for-profit sectors. The authors have not stated any conflicts of interest.

\section{REFERENCES}

Barkema, H. W., H. A. Deluyker, Y. H. Schukken, and T. J. G. M. Lam. 1999. Quarter-milk somatic cell count at calving and at the 
first six milkings after calving. Prev. Vet. Med. 38:1-9. https://doi .org/10.1016/S0167-5877(98)00142-1.

Barkema, H. W., M. A. G. von Keyserlingk, J. P. Kastelic, T. J. G. M. Lam, C. Luby, J.-P. Roy, S. J. LeBlanc, G. P. Keefe, and D. F. Kelton. 2015. Invited review: Changes in the dairy industry affecting dairy cattle health and welfare. J. Dairy Sci. 98:7426-7445. https://doi.org/10.3168/jds.2015-9377.

Bennedsgaard, T. W., S. Elvstrøm, and M. D. Rasmussen. 2004. Selection of cows for treatment of udder infections in AMS herds. Pages 209-214 in Automatic milking - A better understanding. A. Meijering, H. Hogeveen, and C. J. A. M. de Koning, eds. Wageningen Academic Publishers, Wageningen, the Netherlands.

CRV. 2020. Jaarstatistieken 2019. CRV, Arnhem, the Netherlands.

Cui, J. 2007. QIC program and model selection in GEE analyses. Stata J. 7:209-220. https://doi.org/10.1177/1536867X0700700205.

de Koning, K., B. Slaghuis, and Y. van der Vorst. 2003. Robotic milking and milk quality: effects on bacterial counts, somatic cell counts, freezing point and free fatty acids. Ital. J. Anim. Sci. 2:291-299. https://doi.org/10.4081/ijas.2003.291.

Deng, Z., T. J. G. M. Lam, H. Hogeveen, M. Spaninks, N. Heij, M. Postema, T. van Werven, and G. Koop. 2020. Antimicrobial use and farmers' attitude toward mastitis treatment on dairy farms with automatic or conventional milking systems. J. Dairy Sci. 103:7302-7314. https://doi.org/10.3168/jds.2019-17960.

Hogenboom, J. A., L. Pellegrino, A. Sandrucci, V. Rosi, and P. D'Incecco. 2019. Invited review: Hygienic quality, composition, and technological performances of raw milk obtained by robotic milking of cows. J. Dairy Sci. 102:7640-7654. https://doi.org/10 3168/jds.2018-16013.

Hovinen, M., and S. Pyörälä. 2011. Invited review: Udder health of dairy cows in automatic milking. J. Dairy Sci. 94:547-562. https:/ /doi.org/10.3168/jds.2010-3556.

Hovinen, M., M. D. Rasmussen, and S. P. Pyörälä. 2009. Udder health of cows changing from tie stalls or free stalls with conventional milking to free stalls with either conventional or automatic milking. J. Dairy Sci. 92:3696-3703. https://doi.org/10.3168/jds.2008 -1962 .

Jacobs, J. A., and J. M. Siegford. 2012. Invited review: The impact of automatic milking systems on dairy cow management, behavior, health, and welfare. J. Dairy Sci. 95:2227-2247. https://doi.org/ 10.3168/jds.2011-4943.

Klungel, G. H., B. A. Slaghuis, and H. Hogeveen. 2000. The effect of the introduction of automatic milking systems on milk quality. J. Dairy Sci. 83:1998-2003. https://doi.org/10.3168/jds.S0022 $-0302(00) 75077-6$
KOM. 2020. Statistiek. Accessed Sep. 4, 2020. http://www.stichtingkom nl/index.php/stichting_kom/category/statistiek.

Kruip, T. A. M., H. Morice, M. Robert, and W. Ouweltjes. 2002. Robotic milking and its effect on fertility and cell counts. J. Dairy Sci. 85:2576-2581. https://doi.org/10.3168/jds.S0022-0302(02)74341 -5 .

Mulder, H. A., A. F. Groen, G. De Jong, and P. Bijma. 2004. Genotype $\times$ environment interaction for yield and somatic cell score with automatic and conventional milking systems. J. Dairy Sci. 87:1487-1495. https://doi.org/10.3168/jds.S0022-0302(04)73300 $-7$.

Penry, J. F. 2018. Mastitis control in automatic milking systems. Vet. Clin. North Am. Food Anim. Pract. 34:439-456. https://doi.org/ 10.1016/j.cvfa.2018.06.004.

Rasmussen, M. D. 2006. Automatic milking and udder health: An overview. Proceedings of the 2006 World Buiatrics Congress, Nice, France. World Association for Buiatrics, Dublin, Ireland.

Rasmussen, M. D., M. Bjerring, P. Justesen, and L. Jepsen. 2002. Milk quality on Danish farms with automatic milking systems J. Dairy Sci. 85:2869-2878. https://doi.org/10.3168/jds.S0022 -0302(02)74374-9.

Santman-Berends, I. M. G. A., H. Brouwer-Middelesch, L. Van Wuijckhuise, A. J. G. de Bont-Smolenaars, and G. van Schaik. 2016. Surveillance of cattle health in the Netherlands: Monitoring trends and developments using routinely collected cattle census data. Prev. Vet. Med. 134:103-112. https://doi.org/10.1016/j.prevetmed .2016.10.002.

Stigler, S. M. 1997. Regression towards the mean, historically considered. Stat. Methods Med. Res. 6:103-114. https://doi.org/10 .1177/096228029700600202.

van den Borne, B. H. P., G. van Schaik, T. J. G. M. Lam, and M. Nielen. 2010. Variation in herd level mastitis indicators between primiand multiparae in Dutch dairy herds. Prev. Vet. Med. 96:49-55 https://doi.org/10.1016/j.prevetmed.2010.05.010.

ZuivelNL. 2019. Zuivel in Cijfers. Accessed September 4, 2020. https:/ /www.zuivelnl.org/marktinformatie/zuivel-in-cijfers.

\section{ORCIDS}

Bart H. P. van den Borne @ https://orcid.org/0000-0001-6248-4707

Niek J. M. van Grinsven ( https://orcid.org/0000-0002-7154-0130

Henk Hogeveen (i) https://orcid.org/0000-0002-9443-1412 